STUDI

FRANCESI

\section{Studi Francesi}

Rivista quadrimestrale fondata da Franco Simone

170 (LVII | II) | 2013

Varia

\title{
Franco Piva, Pamela in Francia, Tomo II, Testimonianze, testi critici e derivati
}

\section{Vittorio Fortunati}

\section{(2) OpenEdition \\ 1 Journals}

\section{Edizione digitale}

URL: https://journals.openedition.org/studifrancesi/3113

DOI: $10.4000 /$ studifrancesi.3113

ISSN: 2421-5856

\section{Editore}

Rosenberg \& Sellier

\section{Edizione cartacea}

Data di pubblicazione: 1 juillet 2013

Paginazione: 460-461

ISSN: 0039-2944

\section{Notizia bibliografica digitale}

Vittorio Fortunati, «Franco Piva, Pamela in Francia, Tomo II, Testimonianze, testi critici e derivati», Studi Francesi [Online], 170 (LVII | II) | 2013, online dal 30 novembre 2015, consultato il 02 février 2023. URL: http://journals.openedition.org/studifrancesi/3113; DOI: https://doi.org/10.4000/studifrancesi.3113

Questo documento è stato generato automaticamente il 2 février 2023.

\section{(c) (i) (3)}

Creative Commons - Attribuzione - Non commerciale - Non opere derivate 4.0 Internazionale - CC BYNC-ND 4.0

https://creativecommons.org/licenses/by-nc-nd/4.0/ 


\title{
Franco Piva, Pamela in Francia, Tomo II, Testimonianze, testi critici e derivati
}

\author{
Vittorio Fortunati
}

\section{NOTIZIA}

FRANCO PIVA, Pamela in Francia, Tomo II, Testimonianze, testi critici e derivati, Fasano, Schena, 2012, pp. 407.

1 Con l'uscita del secondo tomo, giunge a compimento la pubblicazione del ponderoso saggio dedicato da F. Piva all'influsso della Pamela di Richardson sulla cultura francese negli anni che seguirono l'apparizione del romanzo: un influsso che, come abbiamo già cercato di mettere in evidenza (cf. la scheda relativa al primo tomo nel n. 169 di questa rivista), si concretizzò soprattutto in un crescente interesse per la letteratura britannica e, prima ancora del ben noto successo di Clarissa Harlowe, nella creazione di un contesto propizio alla fortuna e allo sviluppo del genere epistolare. I testi su cui lo studioso ha fondato il proprio meticoloso lavoro di ricostruzione storica compaiono, ora, nel volume di cui rendiamo conto.

2 La prima parte («Testimonianze e scritti critici») raccoglie le opinioni contenute nella corrispondenza di alcuni letterati (tra i quali citiamo Madame de Graffigny e Crébillon fils) e numerosi scritti, pubblicati autonomamente o su riviste e giornali dell'epoca (la «Bibliothèque françoise», la «Bibliothèque raisonnée», le «Observations sur les Écrits modernes» e altri). Nella grande varietà delle prese di posizione, va rilevato come Richardson, criticato anche aspramente sul piano dello stile, venga spesso lodato (talvolta dalle stesse persone) per la sua capacità di avvincere i lettori e di rappresentare efficacemente la realtà. Se, quindi, la ricezione di Pamela fu condizionata dal permanere di pregiudizi estetici di origine classicistica, non si può negare che gli elementi di originalità che il romanzo contiene siano stati immediatamente percepiti.

3 Nella seconda parte («I testi derivati») troviamo quelle opere (un testo in prosa e tre pièces teatrali) che dal romanzo epistolare inglese trassero, in diversa misura, 
ispirazione; mancano gli anonimi Mémoires de Pamela, poiché un'edizione critica è già stata fornita dallo stesso F. Piva (Fasano, Schena, 2007). L'Antipamela (1742), attribuita a Claude Villaret, consiste nelle memorie di una donna assai diversa dall'eroina di Richardson: la protagonista narrante, infatti, vive una serie di vicende sentimentali in cui non si dimostra avara delle proprie grazie e infine, pentita più o meno sinceramente, rinuncia all'amore, non senza essersi assicurata una certa tranquillità economica. In Paméla en France, ou la vertu mieux éprouvée (1743), commedia in tre atti composta da Louis de Boissy per il Théâtre Italien, l'atmosfera è decisamente alleggerita dalla presenza del patois e di scene cantate. Al contrario, la coeva Pamela di Nivelle de la Chaussée è una tipica comédie sérieuse, in cui sono affrontati temi quali il pregiudizio sociale e la contrapposizione fra virtù e necessità. A entrambe le commedie citate si fa chiaramente allusione in un'altra pièce andata in scena lo stesso anno, $L a$ déroute des Pamélas, atto unico in cui Claude Godard d'Aucour si burla degli imitatori francesi di Richardson $\mathrm{e}$, nel vaudeville finale, celebra la gloria della «Bibliothèque Bleue».

4 Tutti i testi contenuti nel volume, sia letterari che critici, sono riprodotti nella loro grafia originale: F. Piva motiva questa scelta con l'intento di consentire al lettore di «trovarsi immerso nella lingua che non solo Mme de Graffigny, ma anche Voltaire, il grande Voltaire, praticava quotidianamente in quegli anni», traendone la sensazione «di partecipare egli stesso alle accalorate discussioni che l'irruzione di un'opera così nuova come la Pamela richardsoniana provocò nel contesto culturale e letterario della Francia di metà Settecento» (p. 8). Se la capacità di far rivivere, e non solo descrivere, le epoche passate è uno dei tratti distintivi del vero storico, crediamo che l'autore di Pamela in Francia meriti appieno questo titolo. 